\title{
Lactic acid bacteria protect human intestinal epithelial cells from Staphylococcus aureus and Pseudomonas aeruginosa infections
}

\author{
S. Affhan ${ }^{1}$, W. Dachang ${ }^{1}$, Y. Xin ${ }^{1}$ and D. Shang ${ }^{2}$ \\ 1'Department of Biotechnology, Dalian Medical University, Liaoning, China \\ ${ }^{2}$ Department of General Surgery, Pancreatobiliary Centre, \\ Dalian Medical University First Affiliated Hospital, Dalian, China \\ Corresponding author: D. Shang \\ E-mail: microphilia@hotmail.com \\ Genet. Mol. Res. 14 (4): 17044-17058 (2015) \\ Received August 6, 2015 \\ Accepted October 25, 2015 \\ Published December 16, 2015 \\ DOI http://dx.doi.org/10.4238/2015.December.16.5
}

\begin{abstract}
Staphylococcus aureus and Pseudomonas aeruginosa are opportunistic pathogens that cause nosocomial and food-borne infections. They promote intestinal diseases. Gastrointestinal colonization by $S$. aureus and $P$. aeruginosa has rarely been researched. These organisms spread to extra gastrointestinal niches, resulting in increasingly progressive infections. Lactic acid bacteria are Gram-positive bacteria that produce lactic acid as the major end-product of carbohydrate fermentation. These bacteria inhibit pathogen colonization and modulate the host immune response. This study aimed to investigate the effects of Lactobacillus acidophilus and Lactobacillus rhamnosus on enteric infections caused by the paradigmatic human pathogens $S$. aureus ATCC25923 and $P$. aeruginosa ATCC27853. The effect of whole cells and neutralized cell-free supernatant (CFS) of the lactobacilli on LoVo human carcinoma enterocyte (ATCC CCL-229) infection was analyzed by co-exposure, pre-exposure, and post-exposure studies. Simultaneous application of whole cells and CFS of the lactobacilli significantly eradicated enterocyte infection ( $P<$ $0.05)$; however, this effect was not seen when the whole cells and CFS
\end{abstract}


were added after or prior to the infection $(P>0.05)$. This result could be attributed to interference by extracellular polymeric substances and cell surface hydrophobicity, which resulted in the development of a pathogen that did not form colonies. Furthermore, results of the plate count and LIVE/ DEAD BacLight bacterial viability staining attributed this inhibition to a nonbacteriocin-like substance, which acted independently of organic acid and $\mathrm{H}_{2} \mathrm{O}_{2}$ production. Based on these results, the cell-free supernatant derived from lactobacilli was concluded to restrain the development of $S$. aureus and $P$. aeruginosa enteric infections.

Keywords: Infection; Intestinal epithelial cells; Lactic acid bacteria; Pseudomonas aeruginosa; Staphylococcus aureus

\section{INTRODUCTION}

Antimicrobial resistance is a growing threat to human health; the increase in antimicrobial resistance is a direct consequence of the excessive use of antibiotics. Staphylococcus aureus and Pseudomonas aeruginosa are well-known opportunistic, potent, biofilm-producing, nosocomial and food-borne pathogens. They generally have the ability to promote intestinal diseases. The use of antibiotics for the treatment of $P$. aeruginosa and $S$. aureus infections in humans remains controversial; however, the increase in antibiotic resistance in these bacterial species is a growing cause for concern.

Human colonization by $S$. aureus is widespread; thirty percent of the population carries S. aureus as part of the nasopharyngeal, skin, and intestinal epithelial microbiota (Graham et al., 2006). Research conducted over the past few years has revealed that $S$. aureus colonizes the intestine of several neonates; its presence in the gut during the early developmental stages has also been associated with allergy development (Björkstén et al., 2001). This bacterium causes diseases ranging from skin infections to food-borne illnesses, and severe infections, including endocarditis, osteomyelitis, and sepsis (Lowy, 1998). The biofilm-forming ability of this bacterium depends on the production of polysaccharide intercellular adhesin (PIA), encoded by the icaADBC gene cluster (Cramton et al., 1999).

$P$. aeruginosa is an aerobic, Gram-negative, ubiquitous bacterium. It has a high degree of adaptability and is resistant to many antibiotics (Pearson et al., 2000). The intestinal carriage of $P$. aeruginosa could be attributed to its opportunistic nature. This bacterium causes enteric disease accompanied by sepsis, which is described as "Shanghai fever", a syndrome comprising fever, diarrhea, and sepsis; this disease was attributed to $P$. aeruginosa in as early as 1918 (Lepow, 1994). Gastrointestinal colonization with subsequent invasion into the bloodstream is the presumed mechanism underlying $P$. aeruginosa bacteremia in neutropenic patients. Diarrhea caused by $P$. aeruginosa has been observed almost exclusively in patients with prolonged antibiotic exposure (Kim et al., 2001). The development of antibiotic resistance is a serious side effect of current antipseudomonal treatments.

Lactic acid bacteria comprise a group of Gram-positive, non-sporulating rods or cocci, which produce lactic acid as the major end-product of carbohydrate fermentation (Aasen et al., 2000; Suskovic et al., 2001). These bacteria produce a variety of antimicrobial compounds (Bongaerts and Severijnen, 2001; Servin, 2004) such as organic acids, diacetyl compounds, and hydrogen peroxide during lactic fermentation (Lindgren and Dobrogosz, 1990). The production of 
organic acids results in a decrease in intestinal $\mathrm{pH}$, and the inhibition of growth of other bacterial pathogens (Fang et al., 1996). In this way, these bacteria impart health and nutritional benefits to the host. They also have the potential to inhibit pathogen colonization and modulate the immune response (Laparra and Sanz, 2009).

Compared to the nasal carriage of $S$. aureus and $P$. aeruginosa, gastrointestinal colonization by $S$. aureus and $P$. aeruginosa has been rarely studied. Herein, we have focused on two paradigmatic human pathogenic bacteria of great medical importance, Pseudomonas aeruginosa and Staphylococcus aureus. These organisms spread from the gastrointestinal tract to extra gastric niches to produce progressive infections. This study aimed to investigate the effects of lactobacilli and their cell-free extracts on $S$. aureus and $P$. aeruginosa (enterocyte) infection. This study was initiated as an attempt to understand and control the continuous increase in antibiotic resistance in these human pathogens.

\section{MATERIAL AND METHODS}

\section{Microorganisms and culture conditions}

Human bacterial pathogens (S. aureus ATCC 25923 and $P$. aeruginosa ATCC 27853) were obtained from American type culture collection (ATCC), cultured in Luria-Bertani (LB) broth, and incubated at $37^{\circ} \mathrm{C}$. Lactobacillus rhamnosus CMCC 341 and Lactobacillus acidophilus CMCC 878 were acquired from China Medical Culture Collection (CMCC), cultured in de Man Rogosa Sharpe (MRS) broth, and incubated at $37^{\circ} \mathrm{C}$.

\section{Preparation of cell-free supernatant (CFS) derived from lactobacilli}

The Lactobacillus culture, containing $1.5 \times 10^{8} \mathrm{CFU} / \mathrm{mL}$ was incubated overnight. This was then centrifuged at $10,000 \mathrm{~g}$ for $10 \mathrm{~min}$ at $4^{\circ} \mathrm{C}$. The resulting supernatant was neutralized, in order to exclude all pH-dependent activities (Ogunbanwo et al., 2003).

\section{Adhesion to an abiotic surface}

The preliminary adhesion of human bacterial pathogens to the walls of pre-sterilized 96-well polystyrene microtiter plates was studied using the method described by Maldonado et al. (2007). The plates were subsequently incubated for 24,48 , and $72 \mathrm{~h}$ at $37^{\circ} \mathrm{C}$. The samples were quantitatively analyzed by adding $33 \%(\mathrm{v} / \mathrm{v})$ glacial acetic acid (Merck-Millipore, Darmstadt, Germany) per well and measuring $\mathrm{OD}_{589}$ by using an enzyme-linked immunosorbent assay (ELISA) reader (STAT-FAX). All assays were performed in triplicate.

\section{Infection of human intestinal cells}

LoVo human enterocytes (CCL-229) were obtained from ATCC. The cells were cultured in 24-well plates with Dulbecco's modified Eagle's medium (DMEM), supplemented with 10\% fetal bovine serum and $100 \mu \mathrm{g} / \mathrm{mL}$ penicillin-streptomycin (Invitrogen; Life Technologies, Carlsbad, CA, USA). The cells were incubated until a confluence of $75 \%$ was achieved in a $5 \% \mathrm{CO}_{2}$ incubator at $37^{\circ} \mathrm{C}$. The cells were washed thrice with phosphate buffered saline (PBS), transferred into DMEM culture medium without serum or antibiotics for $2 \mathrm{~h}$ prior to the infection, and subsequently used 
in the adhesion experiments. Bacterial pellets (pathogens and lactobacilli) were suspended in serum-antibiotic-free DMEM; the cell concentration was adjusted to $2 \times 10^{8} \mathrm{CFU} / \mathrm{mL}$ prior to the adherence assay. The enterocytes were infected with the pathogens in the presence or absence of lactobacilli in 24-well plates for $24 \mathrm{~h}$. The average number of viable cells/well was determined by the Trypan blue dye exclusion test; this number was used to achieve a multiplicity of infection (MIO) of 1:10. After this incubation period, the non-adherent cells were washed thrice with PBS. The adherent cells were subsequently detached using a trypsin-ethylenediaminetetraacetic acid (EDTA) solution (0.5\% porcine trypsin and 0.2\% EDTA in PBS; Sigma-Aldrich, St. Louis, MO, USA) along with $0.2 \%$ Triton $\mathrm{X}-100$. The bacterial cell mixture was diluted and plated onto LB plates to determine the number of adhered bacteria (Hawdon et al., 2010). In a parallel experiment, DNA was extracted from the cells by using the EZNA bacterial DNA isolation kit (Omega), according to manufacturer protocols. The samples were subjected to quantitative real-time polymerase chain reaction $(\mathrm{PCR})$ in a $20-\mu \mathrm{L}$ (S. aureus) or $25-\mu \mathrm{L}$ ( $P$. aeruginosa) reaction mixture, using specific primers and amplification programs, as summarized in Table 1.

Table 1. Primers and amplification program for quantitative real-time polymerase chain reaction analysis.

\begin{tabular}{|c|c|c|c|}
\hline Pathogens and controls & Sequence $\left(5^{\prime}-3^{\prime}\right)$ & Amplification program & References \\
\hline Staphylococcus aureus & $\begin{array}{l}\text { AATCTTTGTCGG TACACGATATTCTTCACG } \\
\text { CGTAATGAGATTTCAGTAGATAATACA ACA }\end{array}$ & $\begin{array}{l}96^{\circ} \mathrm{C} \text { for } 3 \mathrm{~min} 30 \text { or } 40 \text { cycles of } \\
\text { denaturation at } 95^{\circ} \mathrm{C} \text { for } 1 \mathrm{~s} \text { and } \\
\text { annealing-extension at } 55^{\circ} \mathrm{C} \text { for } 30 \mathrm{~s}\end{array}$ & Martineau et al., 1996 \\
\hline Pseudomonas aeruginosa & $\begin{array}{l}\text { GGGGGATCTTCGGACCTCA } \\
\text { TCCTTAGAGTGCCCACCCG }\end{array}$ & $\begin{array}{l}\text { Initial denaturation: } 95^{\circ} \mathrm{C} \text { for } 2 \mathrm{~min} \\
\text { Amplification: } 25 \text { cycles of } 94^{\circ} \mathrm{C} \text { for } 20 \mathrm{~s} \text {, } \\
58^{\circ} \mathrm{C} \text { for } 20 \mathrm{~s} \text {, and } 72^{\circ} \mathrm{C} \text { for } 40 \mathrm{~s} \text { Final } \\
\text { extension: } 72^{\circ} \mathrm{C} \text { for } 1 \mathrm{~min}\end{array}$ & Anzai et al., 2000 \\
\hline TNF- $\alpha$ & $\begin{array}{l}\text { ATGAGCACTGAAAGCATGATCCGG } \\
\text { GCAATGATCCCAAAGTAGACCTGCCC }\end{array}$ & $\begin{array}{l}\text { Initial denaturation: } 94^{\circ} \mathrm{C} \text { for } 2 \text { min } \\
\text { Amplification: } 35 \text { cycles of } 94^{\circ} \mathrm{C} \text { for } \\
30 \mathrm{~s}, 60^{\circ} \mathrm{C} \text { for } 45 \mathrm{~s} \text {, and } 72^{\circ} \mathrm{C} \text { for } 60 \mathrm{~s} \\
\text { Final elongation: } 72^{\circ} \mathrm{C} \text { for } 10 \text { min }\end{array}$ & - \\
\hline Beta actin & $\begin{array}{l}\text { TGGCATTGTTACCAACTGGGACGA } \\
\text { GCTTCTCTTTGATGTCACGCACG }\end{array}$ & $\begin{array}{l}\text { Initial denaturation: } 94^{\circ} \mathrm{C} \text { for } 2 \mathrm{~min} \\
\text { Amplification: } 35 \text { cycles of } 94^{\circ} \mathrm{C} \text { for } 30 \mathrm{~s} \text {, } \\
60^{\circ} \mathrm{C} \text { for } 45 \mathrm{~s} \text {, and } 72^{\circ} \mathrm{C} \text { for } 60 \mathrm{~s} \\
\text { Elongation: } 72^{\circ} \mathrm{C} \text { for } 10 \mathrm{~min}\end{array}$ & - \\
\hline
\end{tabular}

\section{RNA extraction and reverse transcriptase-PCR (RT-PCR)}

Total RNA was extracted from the enterocytes by using RNAiso plus, as described by Schnupf and Sansonetti (2012). The RNA concentration was determined using NanoDrop, and cDNA was synthesized using a cDNA kit (Transgene), according to the manufacturer protocols. The mRNA expression of tumor necrosis factor alpha (TNF- $\alpha$ ) was determined by RT-PCR, using specific primers and amplification program, as detailed in Table 1.

\section{Epifluorescence and confocal laser scanning microscopy}

The bacterial adherence and colonization was established on a 6-well plate containing a cover slip for $48 \mathrm{~h}$, using the protocol described above. Wells containing un-inoculated broth were utilized as the negative control. Following incubation, the cover slips were aseptically removed, washed thrice with $0.05 \mathrm{M}$ phosphate buffer $(\mathrm{pH} 7.4)$, and immersed twice in $1 \mathrm{~mL}$ PBS for 5 min. The samples were stained with $0.5 \% \mathrm{w} / \mathrm{v}$ fluorescein isothiocyanate (FITC) stock solution in $1 \mathrm{~mL}$ PBS $(5 \mu \mathrm{L})$ in the dark, washed with PBS and fixed with $4 \%$ paraformaldehyde for $1 \mathrm{~h}$ at ambient temperature (Hamanaka et al., 2001). In a parallel experiment, the cover slips were also stained 
with $1 \%$ crystal violet (Thenmozhi et al., 2009) and $0.025 \%$ calcofluor white M2R (Sigma-Aldrich), which binds to beta-linked polysaccharides (Maeda and Ishida, 1967), for 1 min in the dark. The cover slips were observed and analyzed under a fluorescence microscope (IX71; Olympus, Tokyo, Japan) and a confocal laser scanning microscope (CLSM; SPS II; Leica, Wetzlar, Germany). This experiment was performed in duplicate.

\section{Effect of CFS derived from lactobacilli on pathogenic extracellular polymeric substance (EPS)}

A modified Congo red binding assay, described previously by Lee et al. (2007), was used to assess the effect of CFS on pathogenic exopolysaccharide. The bacterial cells were collected after centrifugation, and resuspended in $1 \mathrm{~mL}$ LB broth containing Congo red $(40 \mu \mathrm{g} / \mathrm{mL})$ and 100 $\mu \mathrm{L}$ CFS derived from lactobacilli. LB broth containing Congo red served as the negative control. All tubes were incubated at $37^{\circ} \mathrm{C}$ under agitation for $2 \mathrm{~h}$. The bacterial cells stained with Congo red were removed by centrifugation, and the amount of Congo red dye remaining in the supernatant was quantified by measurement of the $\mathrm{OD}$ at $490 \mathrm{~nm}\left(\mathrm{OD}_{490}\right)$.

\section{Effect of CFS derived from lactobacilli on pathogenic cell surface hydrophobicity}

The effect of CFS derived from lactobacilli on pathogenic cell surface hydrophobicity was measured with the microbial adhesion to hydrocarbon (MATH) assay, using a hydrocarbon solvent, as described in a previous study (Rosenberg et al., 1980).

\section{Effect of CFS derived from lactobacilli on pathogenic viability}

Live and dead cells were observed using a LIVE/DEAD BacLight bacterial viability kit (Invitrogen), according to protocols detailed by the manufacturer. Briefly, 3.34 mM SYTO 9 nucleic acid stain and $30 \mathrm{mM}$ propidium iodide $(1.5 \mu \mathrm{L}$ each) were added to all the tubes; the tubes were incubated for $15 \mathrm{~min}$ in the dark at $37^{\circ} \mathrm{C}$. Following incubation, the samples $(10 \mu \mathrm{L}$ each) were placed on clean glass slides for microscopic observation. The bacteria were quantified by the plate count method in parallel.

\section{Determination of inhibitory substances}

The inhibitory metabolites present in CFS derived from lactobacilli were identified using the well diffusion assay. In addition, $\mathrm{H}_{2} \mathrm{O}_{2}$-mediated killing by lactobacilli was assessed on MRS agar supplemented with $0.25 \mathrm{mg} / \mathrm{mL} 3,3^{\prime}, 5,5$ '-tetramethylbenzidine dihydrochloride hydrate and $0.01 \mathrm{mg} / \mathrm{mL}$ horseradish peroxidase (Sigma-Aldrich), respectively, as described by Song et al. (1999). Bacterial cultures were streaked as a thick linear inoculum onto the agar surface and incubated anaerobically for $48 \mathrm{~h}$ at $37^{\circ} \mathrm{C}$. Following incubation, the plates were exposed to ambient atmosphere for $2 \mathrm{~h}$. The development of a blue color was indicative of peroxide production.

\section{Statistical analysis}

The obtained results were statistically analyzed using Student's $t$-test, on the SPSS v.11.5 software platform (SPSS Inc., Chicago, IL, USA). P-values $<0.05$ were considered to indicate statistical significance. 


\section{RESULTS}

\section{Effect of lactobacilli on human intestinal cell infection}

The effect of whole cells and cell-free supernatant of lactobacilli on enterocyte infection caused by $S$. aureus and $P$. aeruginosa was assessed by three methods (pre-exposure, coexposure, and post-exposure). The simultaneous application of whole cells and CFS significantly $(P<0.05)$ reduced the adherence of pathogens and development of infection; however, this effect was not observed when the lactobacilli were added after or prior to the infection $(P>0.05)$. This indicated a competitive mechanism (Figure 1). In addition, the TNF- $\alpha$ mRNA expression (determined by RT-PCR) indicated that the lactic acid bacteria reduced the enterocyte infection (Figure 2).

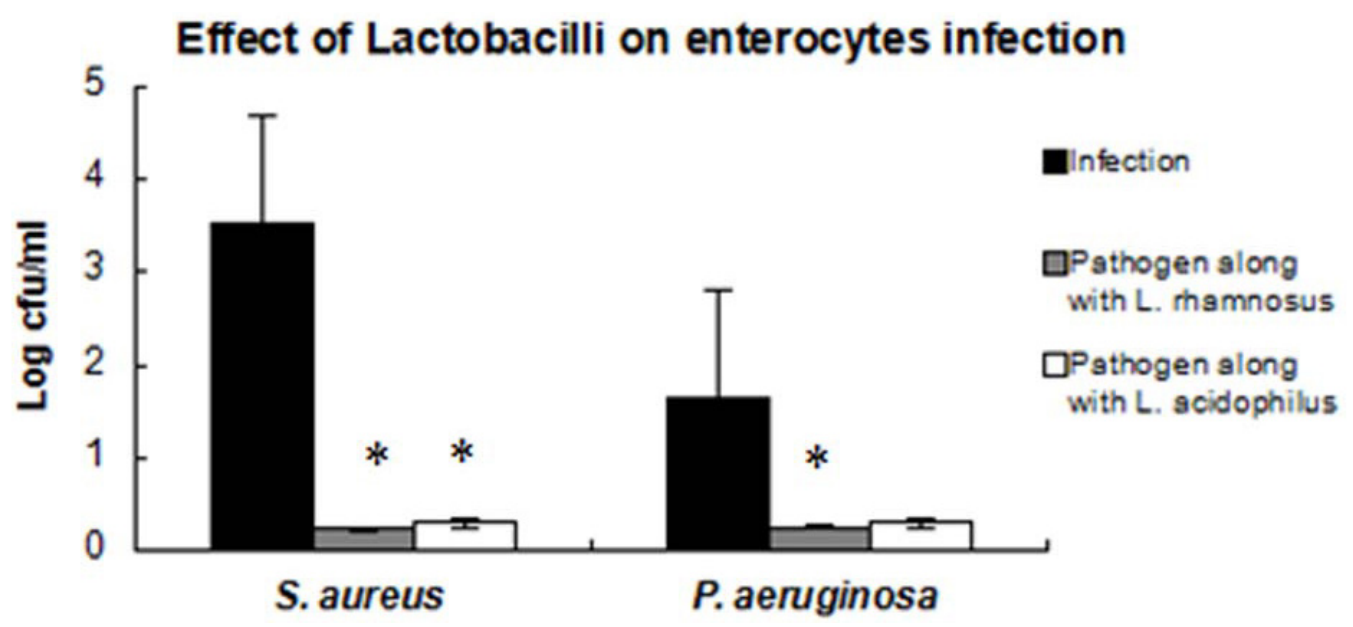

Figure 1. Effect of lactobacilli on enterocyte infection.

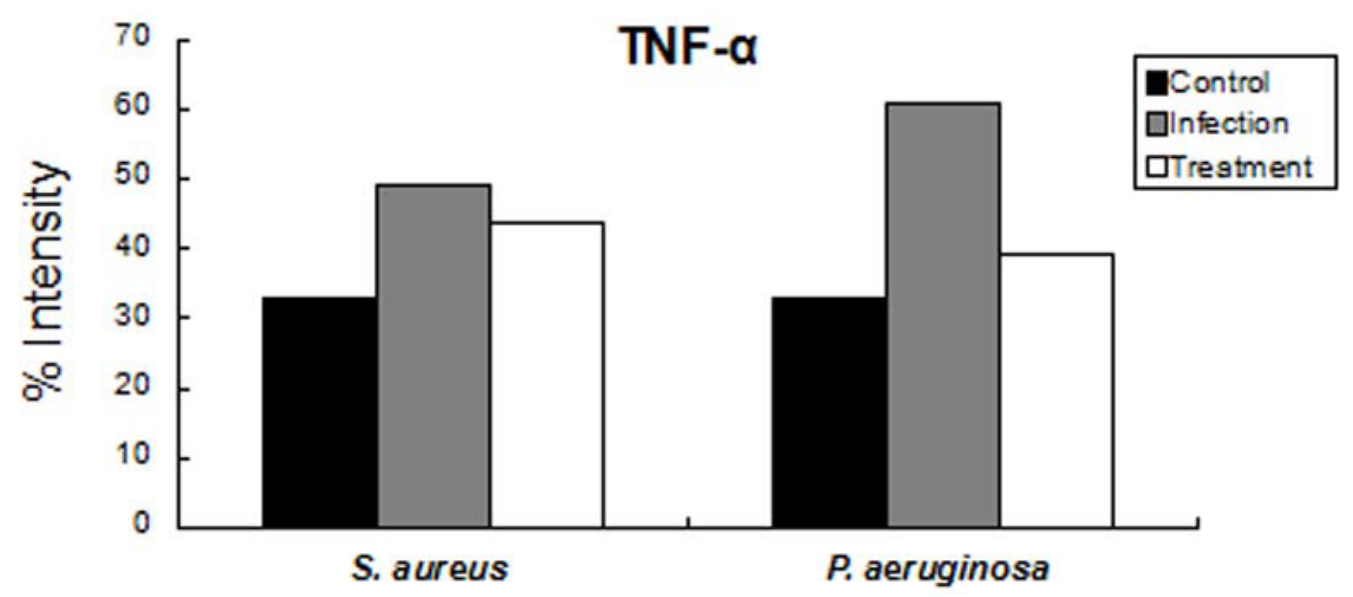

Figure 2. TNF- $\alpha$ mRNA expression. 


\section{Real-time RT-PCR quantification}

The number of $S$. aureus DNA copies was reduced in the presence of $L$. acidophilus $(P<0.05)$; however, the co-exposure of $P$. aeruginosa and $L$. acidophilus failed to demonstrate any significant changes $(P>0.05)$, as summarized in Table 2. Quantitative analysis could not be performed using L. rhamnosus.

Table 2. Results of the quantitative real-time polymerase chain reaction (PCR) analysis (Means \pm standard deviation).

\begin{tabular}{lccr}
\hline Pathogens & Infected LoVo cells & Infected LoVo cells with Lactobacillus acidophilus cells & $P$ values \\
\hline Pseudomonas aeruginosa & $17.815 \pm 1.08$ & $17.605 \pm 0.91$ & $P>0.05$ \\
Staphylococcus aureus & $3.899 \pm 0.27$ & $1.598 \pm 0.40$ & $P<0.05$ \\
\hline
\end{tabular}

Data are reported as the average estimate of logarithms of the PCR target genetic amplicon copy numbers. P value $<$ 0.05 (t-test) was considered (statistically) significantly different.

\section{Epifluorescence and CLSM}

The adherence of pathogens in the presence of CFS derived from lactobacilli was visualized by staining with FITC, crystal violet, and calcofluor white (Figures 3, 4, 5, and 6). FITC binds nonspecifically to the cell wall proteins, whereas calcofluor white binds to the betalinked polysaccharides that aid in bacterial attachment. As expected (based on previously obtained results), CFS derived from lactobacilli reduced the adhesion of pathogenic bacteria to abiotic surface.

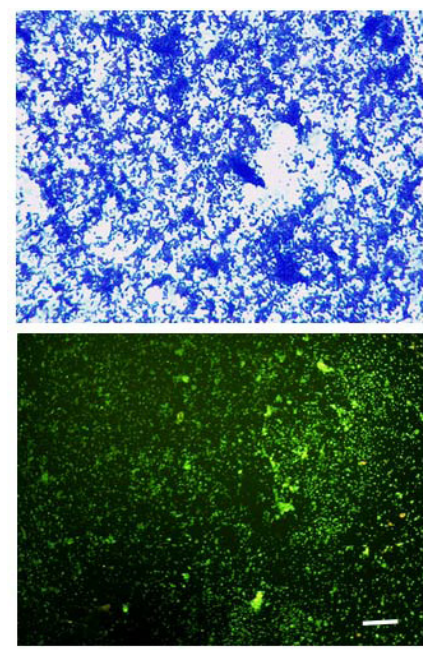

S. aureus
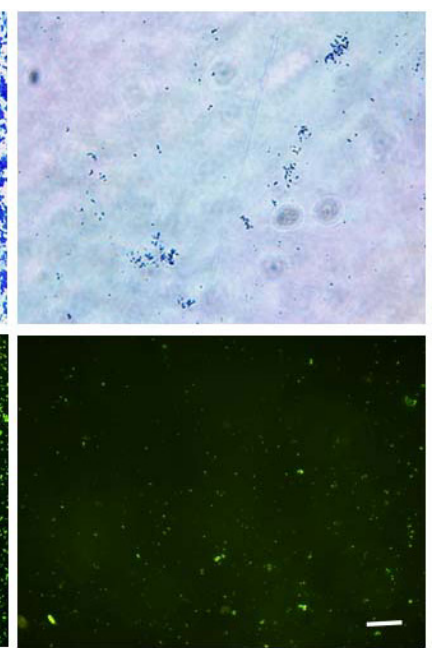

+ L. rhamnosus (CFS)
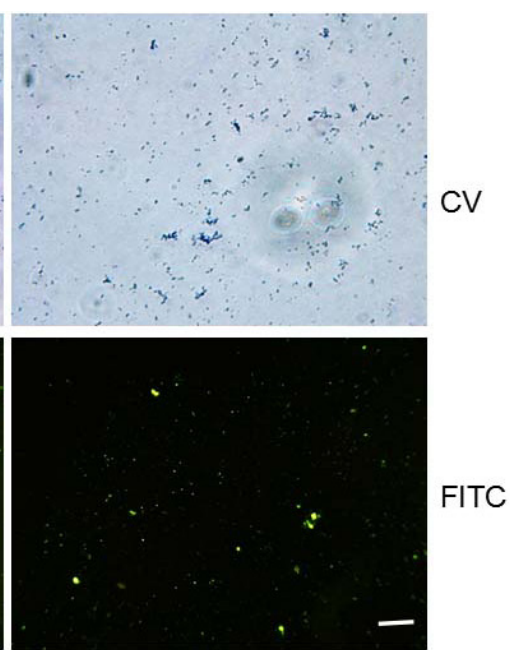

+ L.acidophilus (CFS)

Figure 3. Adherence capacity of antibiotic-resistant Staphylococcus aureus. The adherence capacity of antibioticresistant $S$. aureus in the absence (control) and presence $(+)$ of cell-free supernatant (CFS) derived from lactobacilli. Error bars, $100 \mu \mathrm{m}$. 


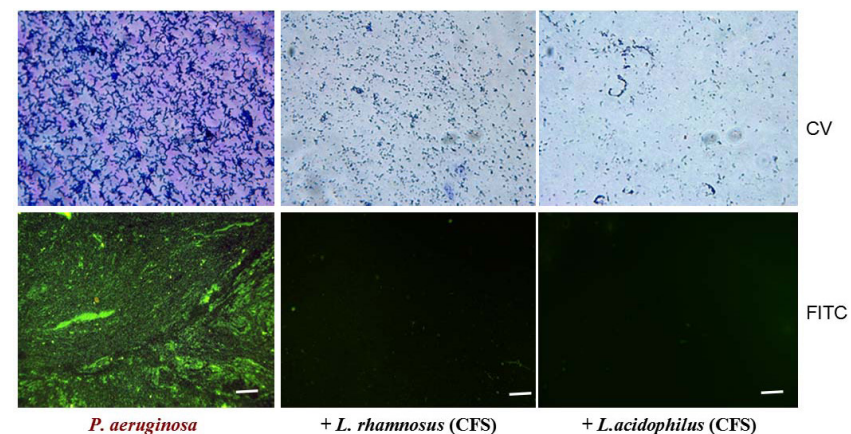

Figure 4. Adherence capacity of antibiotic-resistant $P$ seudomonas aeruginosa. The adherence capacity of pathogenic, antibiotic-resistant $P$. aeruginosa in the absence (control) and presence $(+)$ of CFS derived from lactobacilli. Error bars, $100 \mu \mathrm{m}$

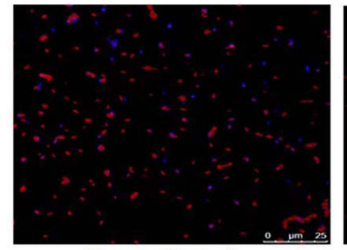

S. aureus (Control)

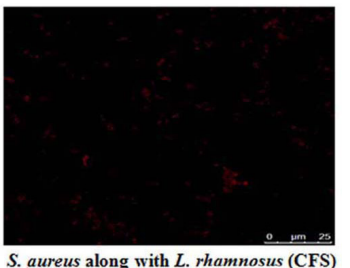

S. aureus along with $L$. rhamnosus (CFS)

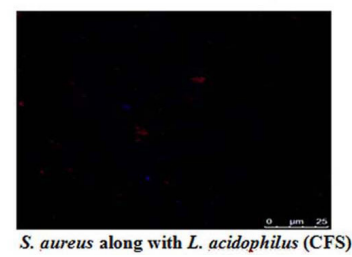

Figure 5. Effect of CFS derived from lactobacilli on the extracellular polymeric substance (EPS) of $S$. aureus. The confocal laser scanning microscopic (CLSM) analysis of EPS, stained with calcofluor white (blue), revealed the effect of CFS derived from lactobacilli on S. aureus EPS. Nucleic acid staining was achieved using ethidium bromide (red).
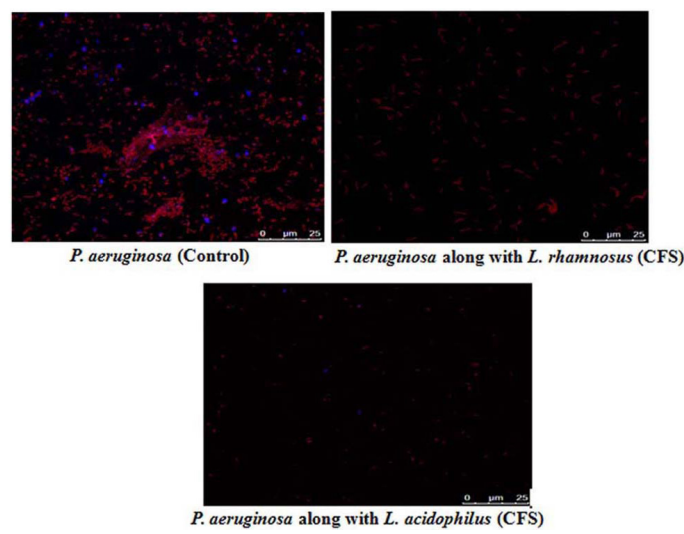

Figure 6. Effect of CFS derived from lactobacilli on the EPS of $P$. aeruginosa. CLSM analysis of EPS, stained with calcofluor white (blue), revealed the effect of CFS derived from lactobacilli on $P$. aeruginosa EPS. Nucleic acid staining was achieved using ethidium bromide (red). 


\section{Effect of CFS derived from lactobacilli on pathogenic extracellular polymeric substance}

Bacterial EPS is the major constituent of biofilm matrix, which allows the bacteria to adhere and form a stable biofilm. The Congo red dye is used to target extracellular polymeric substances. Figure 7 indicated that CFS derived from lactobacilli decreased the ability of pathogens to bind to Congo red. This result supported the theory that CFS interferes with pathogen colonization by affecting the cell surface attachment of the pathogen to the substratum.

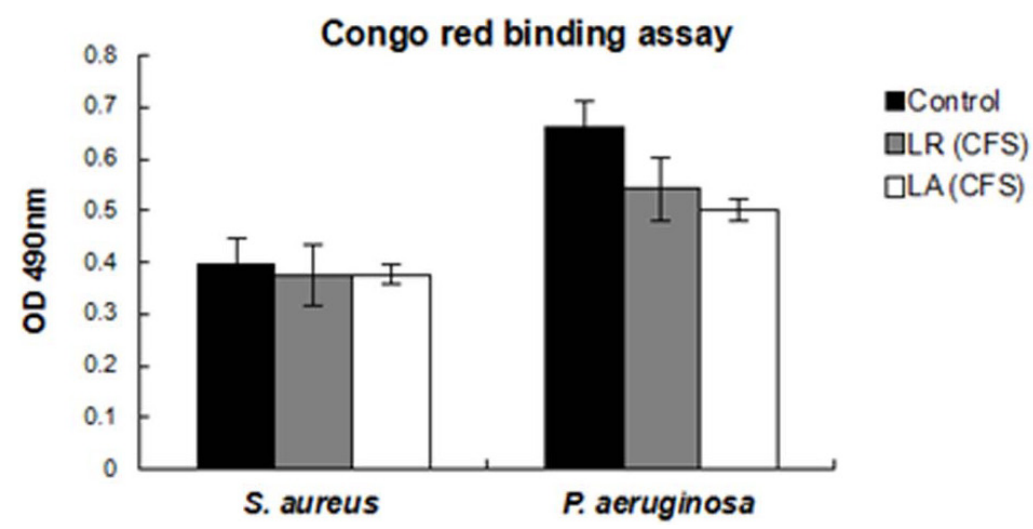

Figure 7. Congo red binding assay. LR, Lactobacillus rhamnosus; LA, Lactobacillus acidophilus.

\section{Effect of CFS derived from lactobacilli on cell surface hydrophobicity of pathogens}

We also attempted to determine the effect of CFS derived from lactobacilli on the surface hydrophobicity of pathogens. Figure 8 indicates that CFS derived from lactobacilli interferes with the surface hydrophobicity of pathogens. Alterations in the surface hydrophobicity result in nonattachment of the pathogens to the substratum; this affects colony formation, and ultimately, the host infection capacity of the pathogens.

\section{Cell surface hydrophobicity}

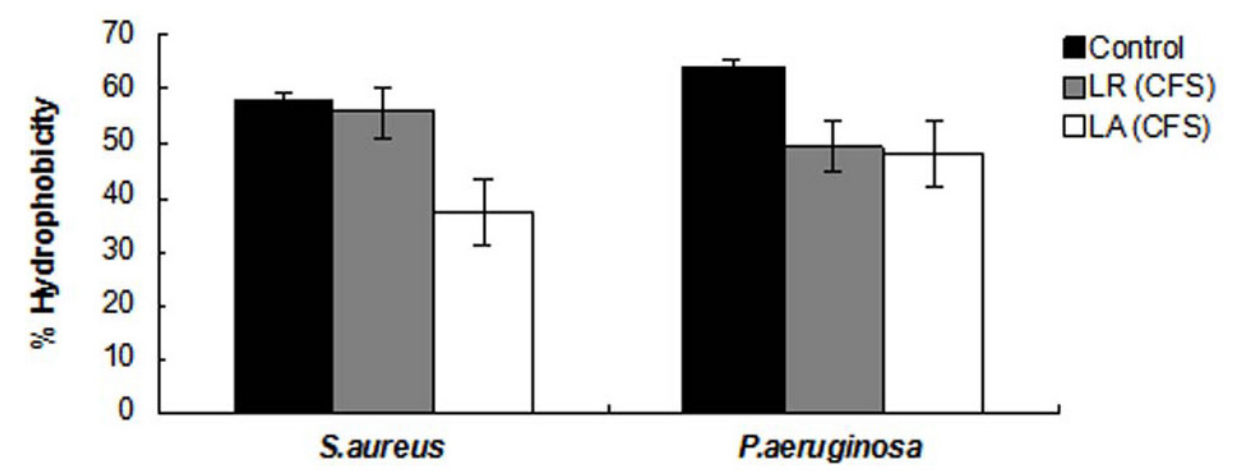

Figure 8. Effect of lactobacilli on pathogenic cell surface hydrophobicity. LR, Lactobacillus rhamnosus; LA, Lactobacillus acidophilus. 


\section{Effect of CFS derived from lactobacilli on the viability of $S$. aureus and $P$. aeruginosa}

Thus far, we have demonstrated that CFS derived from lactobacilli inhibited enterocyte infection. In the next experiment, we investigated the effect of CFS on the viability of pathogens. The results of the plate count assay and Live/Dead BacLight bacterial viability staining revealed the presence of some inhibitory substances in CFS derived from lactobacilli (neutral). L. acidophilusderived CFS showed the maximum bactericidal activity, as depicted in Figures 9, 10, and 11.

A

\section{Effect of Lactobacillus CFS on the viability of $S$. aureus}

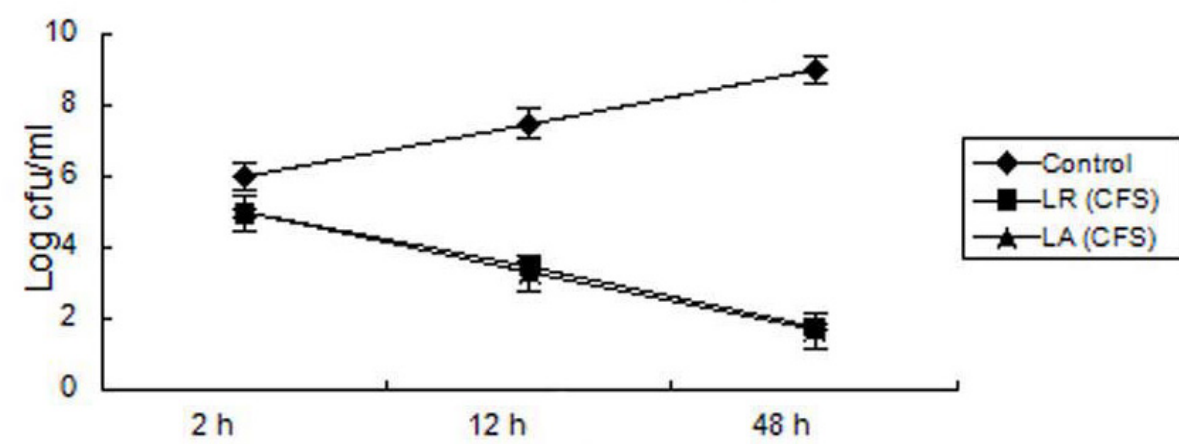

B

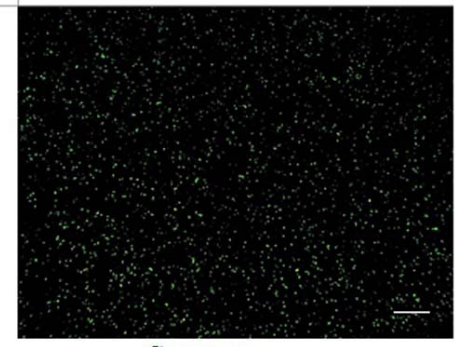

S. aureus

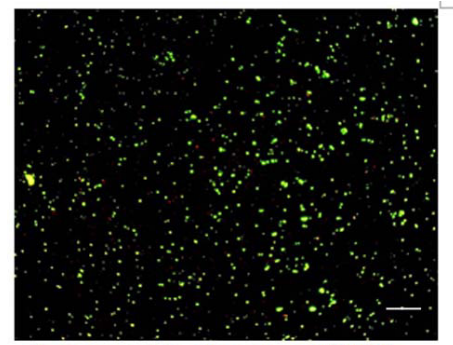

S. aureus + L. rhamnosus $(\mathrm{CFS})$

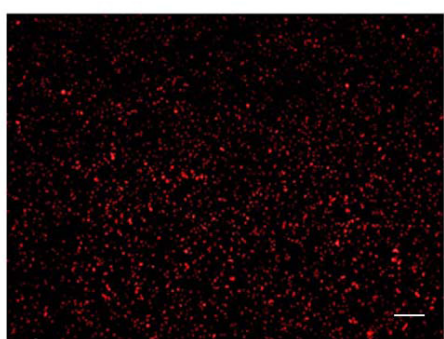

S. aureus + L. acidophilus (CFS)

Figure 9. Effect of CFS derived from lactobacilli on S. aureus cell viability. The viability of pathogens was analyzed by the (A) plate count method and (B) by using the LIVE/DEAD BacLight bacterial viability staining kit. Propidium iodide was used to stain the dead cells (red), while SYTO 9 stained the live cells (green). S. aureus, S; L. rhamnosus, LR; L. acidophilus, LA. Error bars, $100 \mu \mathrm{m}$. 
A

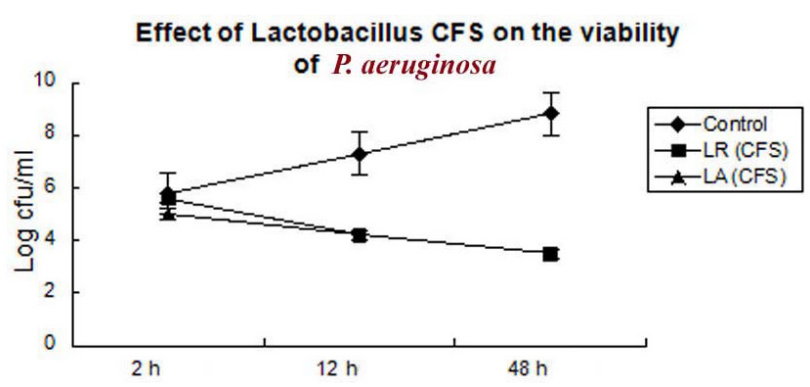

B
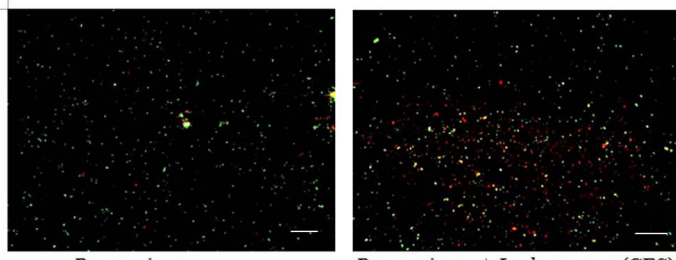

P. aeruginosa

P. aeruginosa + L. rhamnosus $(\mathrm{CFS})$

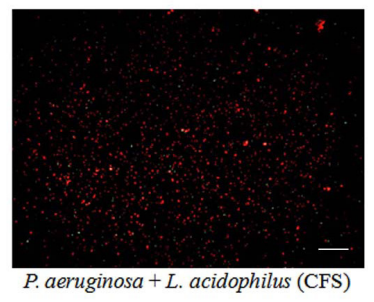

Figure 10. Effect of CFS derived from lactobacilli on $P$. aeruginosa cell viability. The viability of pathogens was analyzed by the (A) plate count method and (B) by using the LIVE/DEAD BacLight bacterial viability staining kit. Propidium iodide stained the dead cells (red), while SYTO 9 stained the live cells (green). P. aeruginosa, P; L. rhamnosus, LR; L. acidophilus, LA. Error bars, $100 \mu \mathrm{m}$.
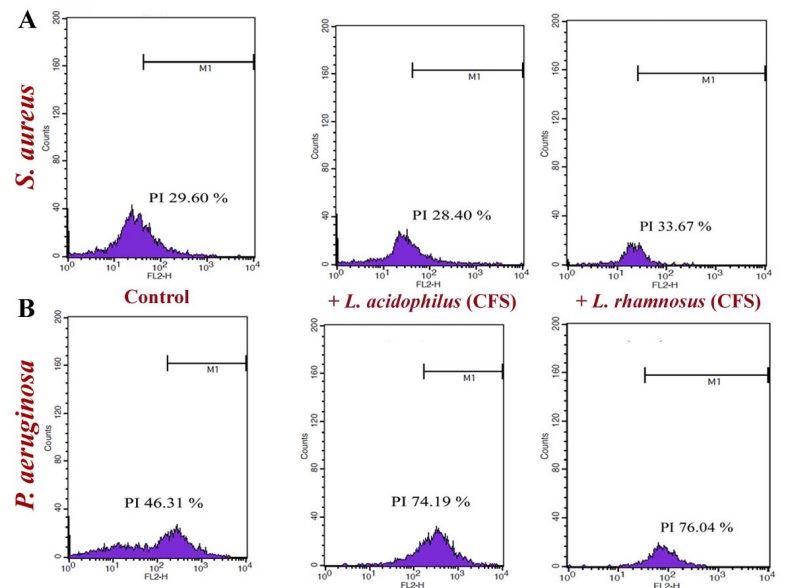

Figure 11. Analysis of bacterial cultures using BacLight bacterial viability staining. S. aureus (Panel A) and $P$. aeruginosa (Panel $\mathrm{B}$ ) cells were stained with propidium iodide $(\mathrm{PI})$ and analyzed by flow cytometry. 


\section{Determination of inhibitory substances present in CFS derived from lactobacilli}

We attempted to identify the inhibitory substances present in CFS via a number of experiments, including the agar well diffusion and $\mathrm{H}_{2} \mathrm{O}_{2}$ production assays. Neither of the tested lactobacilli showed the presence of any bacteriocin-like substances or $_{2} \mathrm{O}_{2}$ mediated killing activity. The $\mathrm{pH}$ dependent activity of CFS was excluded using a neutral CFS in all aspects of the study. This indicates the effect of non-bacteriocin competitive inhibitory molecules (and not organic acids) present in the CFS on the adhesive capacity (to the host cells) and viability of pathogens.

\section{DISCUSSION}

More than $90 \%$ of all bacteria colonizing the body are found in the intestines, which is also an ideal site for efficient transmission of resistance genes. Administration of antimicrobial agents greatly disrupts the activity of the intestinal microbiota; in addition, there is always a chance that the patient's intestine might be colonized by resistant organisms, resulting in the development of serious infections. Antibiotic-resistant $S$. aureus and $P$. aeruginosa are opportunistic pathogens with the ability to promote intestinal infections. The clinical implications of intestinal colonization by $S$. aureus and $P$. aeruginosa are still relatively undefined. In this study, we have examined the effects of lactobacilli on enteric infections caused by Gram-positive S. aureus and Gram-negative $P$. aeruginosa.

Lactic acid bacteria competitively inhibit the development of enterocyte infection by $S$. aureus and $P$. aeruginosa. Host enterocytes simultaneously exposed to lactobacilli or their CFS and pathogens were protected from the effects of the pathogen. This phenomenon was further confirmed by fluorescence microscopic observations, which revealed the competitive inhibition of pathogenic adherence. FITC binds non-specifically to the cell wall proteins (Brul et al., 1997). Competitive exclusion resulting from the inhibition of adhesion has been extensively studied using cultured human intestinal cells. Some studies have shown that competitive inhibition is often strain dependent; on the other hand, displacement is generally not as effective, or requires a longer time to occur (Lee et al., 2003; Zarate and Nader-Macias, 2006).

Extracellular polymeric substances and cell surface hydrophobicity aid in the colonization and biofilm formation of bacteria on the host cell surface. In this study, the CFS derived from lactobacilli did not allow the pathogens to adhere and infect intestinal cells; therefore, we attempted to determine its effect on pathogenic EPS and cell surface hydrophobicity. Congo red binds to exopolysaccharides involved in cell adhesion and biofilm formation (Weiner et al., 1995). The results of both experiments revealed that CFS derived from lactobacilli evidently affected EPS synthesis, thereby interfering with the colonization of pathogens by affecting their attachment to the substratum. This was confirmed by the results of the CLSM analysis. The cell surface hydrophobicity of microorganisms plays an important role in bacterium-host cell interactions (Swiatlo et al., 2002). Any strategy responsible for reducing the cell surface hydrophobicity and EPS synthesis may affect the development of infection, making the cells more susceptible to antibiotics. A previous study also reported that some plant extracts inhibit the biofilm-forming capacity of Gram-positive and Gramnegative bacteria by interfering with their hydrophobicity (Annuk et al., 1999; Nostro et al., 2004; Razak et al., 2006).

$P$. aeruginosa and $S$. aureus infections are difficult to eradicate because of their resistance to many antibiotics. CFS derived from lactobacilli inhibits the development of infections by affecting the attachment of pathogens, in addition to influencing the viability of pathogens. The plate count method and the BacLight bacterial viability test revealed the bactericidal effect of neutral CFS. We 
conducted a number of experiments to identify the inhibitory substances present in CFS derived from lactobacilli. These experiments demonstrated that inhibitory substances other than organic acids compete with the pathogens for adhesion to the host cells, thereby compromising their cellular viability. This bactericidal activity was attributed to a yet unidentified non-bacteriocin-like substance, which functioned independent of organic acids and $\mathrm{H}_{2} \mathrm{O}_{2}$ production. In contrast, an earlier study attributed the inhibition of some Gram-positive and Gram-negative bacteria by $L$. acidophilus BGRA43 to lactic acid production, rather than to hydrogen peroxide or bacteriocin activity (Banina et al., 1998). The reduction in $\mathrm{pH}$ and accumulation of ionized organic acids within bacteria leads to its death (Reid et al., 2003). The lactic acid bacteria countered (and inhibited) pathogenic infection by using bactericidal compounds other than organic acids, as only neutral CFS was used in this study. Therefore, it can be hypothesized that competition for the binding site is a major mechanism through which lactic acid bacteria antagonize $S$. aureus and $P$. aeruginosa. Lactic acid bacteria counteract the adhesive and invasive function of pathogenic bacteria by causing a nonspecific steric hindrance action on the pathogenic receptors (Bernet et al., 1993; Bernet et al., 1994), and by producing inhibitory metabolites. Coconnier-Polter et al. (2005) have previously reported that the CFS of $L$. acidophilus could potentially decrease the intracellular ATP content in S. enterica SL1344. Our results are also consistent with those obtained by Forestier et al. (2001), who demonstrated (in an in vitro study) that L. casei rhamnosus 35 inhibits the growth of both Gram-positive cocci and Gram-negative bacilli, including $P$. aeruginosa.

$S$. aureus and $P$. aeruginosa are common colonizers of the human intestine in hospitalized or immunosuppressed patients or those treated with antibiotics, leading to enteric infections. The results may serve as a theoretical basis for the development of anti- $P$. aeruginosa and $-S$. aureus therapeutic regimens. Lactic acid bacteria inhibited the pathogenic activity by interfering with the production of extracellular polymeric substance and the cell surface hydrophobicity of the pathogen, which in turn affected the colonization and infection capacity of the pathogens. Moreover, this inhibition was independent of the activity of Lactobacillus-produced organic acids. However, additional studies are required to evaluate the possible in vivo effects of whole cells and cell-free supernatants of lactobacilli on opportunistic enteric infections caused by antibioticresistant $P$. aeruginosa and $S$. aureus.

\section{Conflicts of interest}

The authors declare no conflict of interest.

\section{ACKNOWLEDGMENTS}

Research supported by the National Basic Research Program of China (\#2007CB513006).

\section{REFERENCES}

Aasen IM, Moretro T, Katla T, Axelsson L, et al. (2000). Influence of complex nutrients, temperature and pH on bacteriocin production by Lactobacillus sakei CCUG 42687. Appl. Microbiol. Biotechnol. 53: 159-166.

Annuk H, Hirmo S, Turi E, Mikelsaar M, et al. (1999). Effect on cell surface hydrophobicity and susceptibility of Helicobacter pylori to medicinal plant extracts. FEMS Microbiol. Lett. 172: 41-45.

Anzai Y, Kim H, Park JY, Wakabayashi H, et al. (2000). Phylogenetic affiliation of the pseudomonads based on 16S rRNA sequence. Int. J. Syst. Evol. Microbiol. 50: 1563-1589.

Banina A, Vukasinovic M, Brankovic S, Fira D, et al. (1998). Characterization of natural isolate Lactobacillus acidophilus BGRA43 useful for acidophilus milk production. J. Appl. Microbiol. 84: 593-599. 
Bernet MF, Brassart D, Neeser JR and Servin AL (1993). Adhesion of human bifidobacterial strains to cultured human intestinal epithelial cells and inhibition of enteropathogen-cell interactions. Appl. Environ. Microbiol. 59: 4121-4128.

Bernet MF, Brassart D, Neeser JR and Servin AL (1994). Lactobacillus acidophilus LA 1 binds to cultured human intestinal cell lines and inhibits cell attachment and cell invasion by enterovirulent bacteria. Gut 35: 483-489.

Björkstén B, Sepp E, Julge K, Voor T, et al. (2001). Allergy development and the intestinal microflora during the first year of life. J. Allergy Clin. Immunol. 108: 516-520.

Bongaerts GPA and Severijnen RSVM (2001). The beneficial, antimicrobial effect of probiotics. Med. Hypotheses 56: $174-177$.

Brul S, Nussbaum SK and Dielbandhoesing SK (1997). Fluorescent probes for wall porosity and membrane integrity in filamentous fungi. J. Microbiol. Meth. 28: 169-178.

Cramton SE, Gerke C, Schnell NF, Nichols WW, et al. (1999). The intercellular adhesion (ica) locus is present in Staphylococcus aureus and is required for biofilm formation. Infect. Immun. 67: 5427-5433.

Coconnier MH, Li'evin-LeMoal V and Servin AL (2005). A Lactobacillus acidophilus strain of human gastrointestinal microbiota origin elicits killing of enterovirulent Salmonella enterica serovar Typhimurium by triggering lethal bacterial membrane damage. Appl. Environ. Microbiol. 71: 6115-6120.

Fang W, Shi M, Huang L, Chen J, et al. (1996). Antagonism of lactic acid bacteria towards Staphylococcus aureus and Escherichia coli on agar plate and in milk. Vet. Res. 27: 3-12.

Forestier C, De Champs C, Vatoux C and Joly B (2001). Probiotic activities of Lactobacillus casei rhamnosus: in vitro adherence to intestinal cells and antimicrobial properties. Res. Microbiol. 152: 167-173.

Graham PL, Lin SX and Larson EL (2006). U.S. population-based survey of Staphylococcus aureus colonization. Ann. Intern. Med. 144: 318-325

Hamanaka T, Higashiyama K, Fujikawa S and Park EHY (2001). Mycelial pellet infrastructure and visualization of mycelia and intracellular lipid in a culture of Mortierella alpina. Appl. Microbiol. Biotechnol. 56: 233-238.

Hawdon NA, Aval PS, Barnes RJ, Gravelle SK, et al. (2010). Cellular responses of A549 alveolar epithelial cells to serially collected Pseudomonas aeruginosa from cystic fibrosis patients at different stages of pulmonary infection. FEMS Immunol. Med. Microbiol. 59: 207e20.

Kim SW, Peck KR, Jung SI, Kim YS, et al. (2001). Pseudomonas aeruginosa as a potential cause of antibiotic-associated diarrhea. J. Korean Med. Sci. 16: 742-744.

Laparra JM and Sanz Y (2009). Comparison of in vitro models to study bacterial adhesion to the intestinal epithelium. Lett. Appl. Microbiol. 49: 695-701.

Lee VT, Matewish JM, Kessler JL, Hyodo M, et al. (2007). A cyclic-di-GMP receptor required for bacterial exopolysaccharide production. Mol. Microbiol. 65: 1474-1484.

Lee YK, Puong KY, Ouwehand AC and Salminen S (2003). Displacement of bacterial pathogens from mucus and caco-2 cell surface by lactobacilli. J. Med. Microbiol. 52: 925-930.

Lepow ML (1994). Pseudomonas aeruginosa colonization and infection of the gastrointestinal tract. In: Pseudomonas aeruginosa infections and treatment (Baltch AL, Smith RP, eds.). Marcel Dekker Press, New York, 421-440.

Lindgren SW and Dobrogosz WJ (1990). Antagonistic activities of lactic acid bacteria in food and feed fermentations. FEMS Microbiol. Rev. 87: 149-164.

Lowy FD (1998). Staphylococcus aureus infections. N. Engl. J. Med. 339: 520-532.

Maeda $\mathrm{H}$ and Ishida N (1967). Specificity of binding of hexopyranosyl polysaccharides with fluorescent brightener. J. Biochem. 62: $276-278$

Maldonado NC, Silva de Ruiz C, Cecilia M, Nader-Macias ME (2007). A simple technique to detect Klebsiella biofilm-formingstrains. Inhibitory potential of Lactobacillus fermentum CRL 1058 whole cells and products. In: Communicating current research and educational topics and trends in applied microbiology (A. Méndez-Vilas, ed.). Formatex, 52-59.

Martineau F, Picard FJ, Roy PH, Ouellette M, et al. (1996). Species-specific and ubiquitous DNA-based assays for rapid identification of Staphylococcus epidermidis. J. Clin. Microbiol. 34: 2888-2893.

Nostro A, Cannatelli MA, Crisafi G, Musolino AD, et al. (2004). Modifications of hydrophobicity, in vitro adherence and cellular aggregation of Streptococcus mutans by Helichrysum italicum extract. Lett. Appl. Microbiol. 38: 423-427.

Ogunbanwo ST, Sanni Al and Onilude AA (2003). Characterization of bacteriocin produced by Lactobacillus plantarum F1 and Lactobacillus brevis OG1. Afr. J. Biotechnol. 2: 219-227.

Pearson JP, Feldman M, Iglewski BH and Prince A (2000). Pseudomonas aeruginosa cell-to cell signalling is required for virulence in a model of acute pulmonary infection. Infect. Immun. 68: 4331.

Razak FA, Othman RY and Rahim ZH (2006). The effect of Piper betle and Psidium guajava extracts on the cell-surface hydrophobicity of selected early settlers of dental plaque. J. Oral Sci. 48: 71-75.

Reid G, Jass J, Sebulsky MT and McCormick JK (2003). Potential uses of probiotics in clinical practice. Clin. Microbiol. Rev. 16: $658-672$. 
Rosenberg M, Gutnick D and Rosenberg E (1980). Adherence of bacteria to hydrocarbons: a simple method for measuring cell-surface hydrophobicity. FEBS Microbiol. Lett. 9: 29-33.

Schnupf P and Sansonetti PJ (2012). Quantitative RT-PCR profiling of the rabbit immune response: assessment of acute Shigella flexneri infection. PLoS One 7: e36446.

Servin AL (2004). Antagonistic activities of lactobacilli and bifidobacteria against microbial pathogens. FEMS Microbiol. Rev. 28: $405-440$.

Song YL, Kato N, Matsumiya Y, Liu CX, et al. (1999). Identification of and hydrogen peroxide production by fecal and vaginal Lactobacilli isolated from Japanese women and newborn infants. J. Clin. Microbiol. 37: 3062-3064.

Suskovic B, Kos J and Goreta S (2001). Role of lactic acid bacteria and bifidobacteria in symbiotic effect. Food Technol. Biotechnol. 39: 227-235.

Swiatlo E, Champlin FR, Holman SC, Wilson WW, et al. (2002). Contribution of choline-binding proteins to cell surface properties of Streptococcus pneumoniae. Infect. Immun. 70: 412-415.

Thenmozhi R, Nithyanand P, Rathna J and Pandian SK (2009). Antibiofilm activity of coral-associated bacteria against different clinical M serotypes of Streptococcus pyogenes. FEMS Immunol. Med. Microbiol. 57: 284-294.

Weiner R, Langille S and Quintero E (1995). Structure, function and immunochemistry of bacterial exopolysaccharides. J. Ind. Microbiol. 15: 339-346.

Zarate $G$ and Nader-Macias ME (2006). Influence of probiotic vaginal lactobacilli on in vitro adhesion of urogenital pathogens to vaginal epithelial cells. Lett. Appl. Microbiol. 43: 174-180. 